\title{
CERVICAL SCHWANNOMA
}

\author{
Karmacharya B G*, Khadka N, Joshi M R , Sharma V K
}

\section{ABSTRACT}

Schwannomas are solitary, slow growing benign tumors arising from the Schwann cells that form the myelin sheath around the peripheral nerves. Head and neck is the commonest site of these tumors in the body. We present a case of schwannoma in a 35 years old man who had a painless slowly growing tumor in the right side of his neck.

\section{Key Words: Schwannoma, FNAC, parapharyngeal space.}

\section{CASE PRESENTATION}

A 35 years old male, previously healthy, presented to the general surgical out patient clinic with history of gradually increasing, painless swelling on the right side of the neck. He did not have any history of dysphagia, fever, night sweats, dental pain or caries, hoarseness of voice, loss of appetite and loss of weight. He had been investigated outside and was getting anti tubercular treatment for last four months, without any symptomatic benefit.

On clinical examination, he was a well-built, middle-aged man, with stable vital signs. Systemic examination was unremarkable. Local examination revealed about $7 \times 7 \mathrm{cms}$ sized rounded, smooth, non-tender, non-mobile, firm mass on the upper part of anterior triangle on the right side. Overlying skin was free and normal. It did not move on deglutition and on protrusion of tongue. There was no Homer's syndrome. There was a transmitted pulsation. Carotid pulse was not obliterated and thyroid was not palpable.
His routine hematological and biochemical parameters were within normal range. ENT consultation was done and they did not find any abnormalities. Indirect laryngoscopic findings were normal. Ultrasound of the neck revealed a 6 X6 cms sized, oval and solid mass with heterogenous echotexture in the lateral aspect with moderate vascularity. Carotid arteries were displaced anteromedially but carotid bifurcation was not widened (Fig. 1). CT scan revealed well-defined, heterogenous, vascular mass, free from other structures. Carotid angiogram revealed that the vessels were free. FNAC showed a vascular lesion but was inconclusive. Based on history and clinical examination, our working diagnosis was carotid body tumor and planned surgery accordingly.

He underwent exploration by a standard carotid artery approach. An oblique incision at the anterior border of sternocleidomastoid was given. Deep fascia was opened. Carotid arteries were exposed after incising the carotid sheath. The tumor was found between bifurcation, about $6 \times 6 \times 4 \mathrm{cms}$, highly vascular without involving vessels. With proximal and

* NAMS, Bir Hospital, Kathmandu, Nepal

** Kathmandu Medical College Teaching Hospital, Sinamangal, Kathmandu, Nepal

Address for correspondence : Bal Gopal Karmacharya

NAMS, Bir Hospital, Kathmandu, Nepal

Email: kbalgopal@yahoo.com 


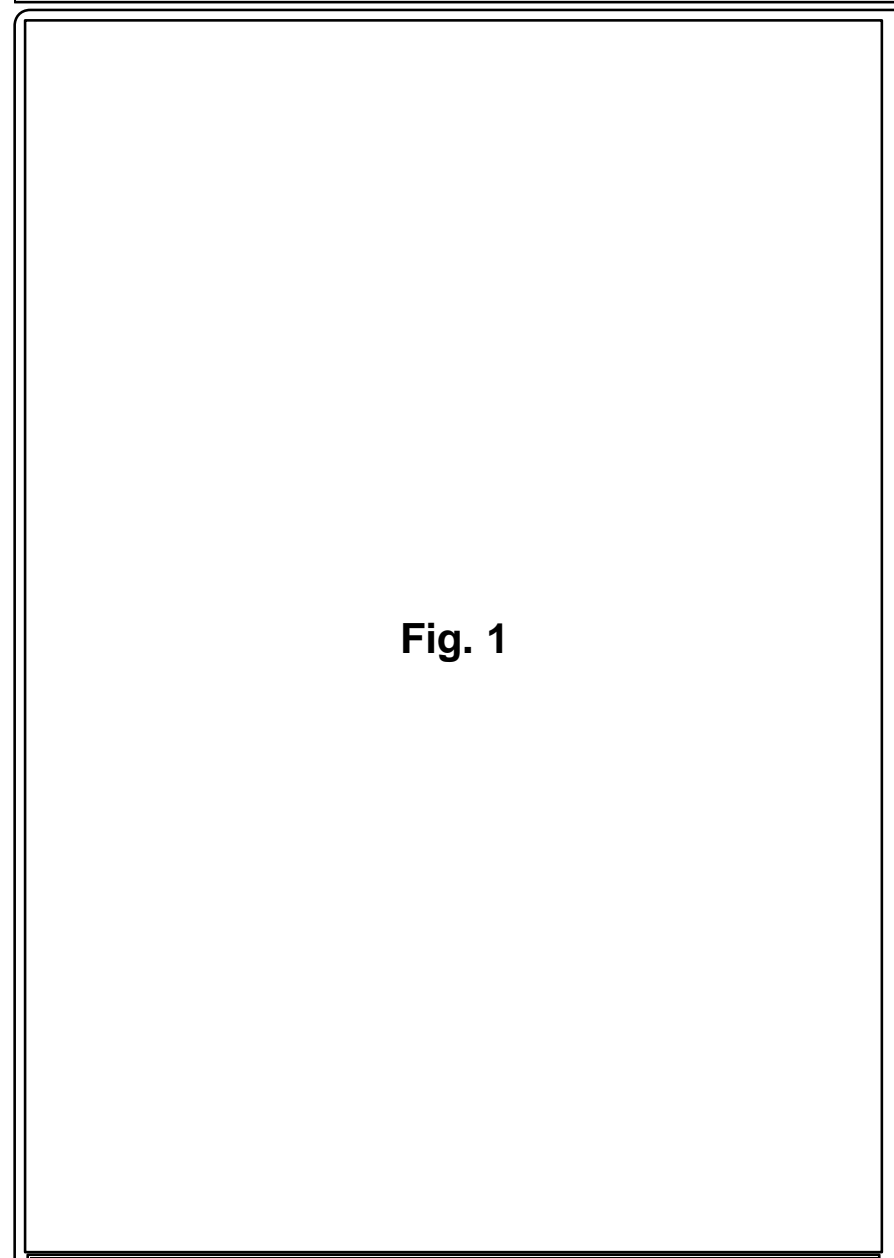

Fig. 1 : Carotid Angiogram

Fig. 2

Fig. 2 : Intraoperative photo

distal vascular control and after identifying $9^{\text {th }}, 10^{\text {th }}$ and $12^{\text {th }}$ nerves the whole tumor along with its capsule was excised, (Fig. 2). The patient had uneventful recovery except transient hoarseness, which disappeared after one week. Histopathological examination report revealed to be schwannoma (Fig. 3).
Fig. 3

Fig. 3 : Photomicrograph of Schwannoma (H.E. stain, X 40)

\section{DISCUSSION}

Schwannomas of the head and neck are uncommon tumors that arise from cranial, peripheral or autonomic nerves. ${ }^{1}$ They are more common in males. Thirty five percent of them occur in the neck region, most common site being the parapharyngeal space. ${ }^{2}$ Neurogenic tumors are the most common tumors of parapharyngeal space (PPS) Schwannomas are benign tumors of neural source produced from Schwann cells ${ }^{3}$. Parapharyngeal Schwannomas are sporadic. ${ }^{3}$ They are usually lobulated, encapsulated, soft and whitish. In early stages, there is a lack of symptoms because of the anatomical localization and slow growth of the tumor. The choice of surgical approach is of paramount importance in both preserving the nerve function and achieving vascular control. ${ }^{4}$ They rarely become malignant. For them a wide local margin of excision is necessary.

\section{REFERENCES}

1. Leu YS, Chang KC. Extracranial head and. neck schwannomas: a review of 8 years experience. Acta Otolaryngol 2002 Jun; 122 (4) : 435-7.

2. Thurnher D, Quint C, Pammer J, Schima W, Knerer B, Denk DM. Dysphagia due to a large schwannom of the oropharynx: case report and review of the literature. Arch Otolaryngol Head Neck Surge 2002 Jul; 128 (7) : 850-2.

3. Almela Cortes R, Cervantes Gongora JA, Conde Perez de la, Blanka I. Schwannoma of cervical sympathetic chain. An Otorrinolaringol Ibero Am2002; 2991 ) :37-46.

4. Carinci F, Caries FP, Grasso DL, Pelucchi S, Pastore A. Schwannoma of the parapharyngeal space. J Craniofac Surg 2000 Jul: 11 (4) : 367-70. 